\title{
Culture and the Theory of Planned Behaviour: Organ Donation Intentions in Americans and Koreans
}

\author{
Doshik Yun ${ }^{1}$ and Hee Sun Park ${ }^{2}$ \\ Department of Communication, Western Illinois University, United States of America \\ ${ }^{2}$ Department of Communication, Michigan State University, United States of America
}

\begin{abstract}
Cultural influence on the effects of attitudes, subjective norms, and perceived behavioural control $\mathcal{U}$ (PBC) on behavioural intentions can vary with types of behaviours. The current study compared American and Korean undergraduates for the effects of each of the Theory of Planned Behaviour components on intentions to sign an organ donor registry and to have family discussion about organ donation. For intentions to sign, results showed that attitudes were a stronger predictor among Americans than Koreans and that PBC was a significant predictor only among Koreans. While attitudes and subjective norms were similarly related to Americans' intentions to sign, subjective norms were more strongly related to Koreans' intentions to sign than attitudes and PBC. For intentions to have family discussion, Americans considered subjective norms to a greater extent than Koreans did. While subjective norms and PBC were more important than attitudes were among Americans, PBC was more important than subjective norms and attitudes among Koreans. Theoretical and practical implications of these and other findings are discussed.
\end{abstract}

Keywords: organ donation, theory of planned behaviour, cross-cultural study, intention to sign, intention to have family discussion, perceived behavioural control

Cultural differences in how attitudes, subjective norms, or perceived behavioural control are related to behavioural intentions can depend on the types of behaviours for which individuals indicate their intention level. When forming intentions to perform a behaviour, some people may consider only their own attitudes, while others may consider the opinions of those who are important to them. Alternatively, while attitudes can be a stronger reason than perceived behavioural control (PBC) for performing a behaviour, $\mathrm{PBC}$ can be a stronger reason than attitudes for performing another behaviour.

Signing an organ donor registry and having family discussion about organ donation are related but distinct behaviours that individuals need to enact during their lifetime if they wish to donate their organs at the time of their death. The current study focuses on the Theory of Planned Behaviour (TPB; Ajzen, 1985, 1988) and examined the differences between US Americans and Koreans. The shortage of organs available for patients in need of transplants is a significant problem in both the United
States and Korea. Examining why individuals intend to sign an organ donor registry and/or to have family discussion about organ donation would provide an understanding of ways to increase deceased organ donation in both countries. Cross-cultural examination of TPB would test generalisability of the theory beyond national boundaries.

\section{Theory of Planned Behaviour and Cultural Differences}

The Theory of Reasoned Action (TRA; Fishbein \& Ajzen, 1975) holds that intentions are determined by attitudes and subjective norms. A meta-analysis found that attitudes and subjective norms were predictive of intentions in many topical areas, including safe sex, exercise, blood donation, and purchasing behaviours (Sheppard, Hartwick, \& Warshaw, 1988). TRA can be limited, because it is supposed to apply to volitional behaviours. To address this limitation, Ajzen $(1985,1988)$ proposed $\mathrm{TPB}$, which includes $\mathrm{PBC}$ as a third component. $\mathrm{PBC}$ refers to individuals' perception of control over a behaviour (Ajzen, 1985, 1988). PBC was found to explain

Address for correspondence: Doshik Yun, Department of Communication, Western Illinois University, 1 University Circle, 224 Sallee Hall, Macomb, IL 61455, USA.E-mail:d-yun@wiu.edu 
variance in intentions and behaviours beyond attitudes and subjective norms (Armitage \& Conner, 2001; Godin \& Kok, 1996).

Studies of TPB have examined the relative strength of the relationship between each component of TPB and intentions across different cultures (Chan \& Lau, 2001; Godin, Maticka-Tynadale, Adrien, Manson-Singer, Williams, Cappon, 1996; Lee \& Green, 1991; Park \& Lee, 2009). Since individuals exhibit cognitions, emotions, and behaviours reflective of their own culture (Markus \& Kitayama, 1991), they are expected to weigh each component of TPB to a varying extent depending on their culture. The individualism/collectivism dimension is also relevant to cross-cultural comparison of TPB. According to Triandis (1995), individuals from individualistic cultures emphasise their own unique attributes and perceive themselves as independent of others, whereas individuals from collectivistic cultures value interrelatedness with others and are attentive to the norms within their social groups. Thus, individuals from individualistic cultures may be more likely to form intentions based on their own preferences (i.e., attitudes) than their counterparts from collectivistic cultures, whereas subjective norms might be more important among the latter than the former.

Empirical findings, however, are mixed. While some studies reported that attitudes were more predictive of intentions than subjective norms in individualistic cultures and that subjective norms were more influential than attitudes in collectivistic cultures (e.g., Chan \& Lau, 2001; Lee \& Green, 1991), others reported that only attitudes, but not subjective norms, influenced intentions among individuals from collectivistic cultures (e.g., Godin et al., 1996; Park, 2000).

One reason for such inconsistent results might be related to characteristics of behaviours in different cultures. Since individuals may have different interpretations of the same stimulus or behaviour depending on the culture where they went through socialisation (Pepitone \& Triandis, 1988), individuals from one culture may view a behaviour as having personal implications (having significant meanings and consequences for oneself only), whereas individuals from another culture may view it as having social implications. As a result, the influence of attitudes or subjective norms on intentions might differ depending on different interpretations of a behaviour across cultures. Similarly, individuals from one culture might regard a behaviour as easier to perform, whereas those from another culture might consider the same behaviour difficult to perform as a result of norms specific to that culture. Given that PBC exerts more influence on intention for a behaviour, as individuals are more likely to perceive the behaviour as beyond their control (Ajzen, 1985, 1988), how individuals from different cultures regard a behaviour in terms of their control perception is important in the relative influence of PBC.

\section{Signing an Organ Donor Registry, Family Discussion, and Organ Donation}

The lack of available organs for transplants has been a serious health problem in both Korea and the United States. In Korea, 15,897 patients were waiting for an organ transplant in 2007, but only 2,360 transplants were performed (Korean Network for Organ Sharing, 2009). Korea tends to be characterised as having cultural beliefs against organ donation (Kim, Elliott, \& Hyde, 2004). In the United States, 102,066 patients were in need of an organ transplant as of May 30, 2009, but only about 27,962 transplants were conducted in the year of 2008 (United Network for Organ Sharing, 2009). In both countries, individuals are asked to sign an organ donor registry and to express their decision to donate organs to family members to have their organs donated after their death. The Institute of Medicine of the National Academies (2006) suggested these two behaviours (i.e., signing and having family discussion) as steps to increase the organ donation rate.

It should be noted that signing and having family discussion are not only distinct from each other, but also from the behaviour of organ donation. While individuals may sign an organ donor registry alone, they need to engage their family members to perform the behaviour of family discussion about organ donation. Research showed that different factors were related with intentions to perform these two behaviours (Park \& Smith, 2007). Signing and having family discussion are also different behaviours from organ donation in that individuals need to perform the first two behaviours for organ donation to take place. Although individuals may consider characteristics of organ donation in forming intentions to sign and to have family discussion, these three behaviours are distinct.

\section{Culture, Organ Donation, and TPB}

In many Asian cultures, individuals regard their body parts as precious gifts from their parents, and they perceive that giving up their body parts is disrespect to the parents (Braun \& Nichols, 1996). Asians may feel that the organ donation issues, such as signing an organ donor registry, have implications for their family members, especially for their parents; consequently, they are more likely to consider subjective norms than their own attitudes in forming intentions about organ donation. Research showed that Koreans perceived organ donation as a family matter (Kim, Elliott, \& Hyde, 2004). Asians may also consider organ donation behaviours as more difficult to perform than non-Asians may because the former may believe that the deceased should remain intact and disfiguration of the body would cause spiritual suffering after death (Kim, Elliott, \& Hyde, 2004; Molzahn, Starzomski, McDonald, \& O’Loughlin, 2005). 
TPB postulates that individuals are more likely to consider $\mathrm{PBC}$ in forming behavioural intentions if they perceive a behaviour to be more difficult to perform (Ajzen, 1985, 1988). Thus, for organ donation behaviours, Asians may consider $\mathrm{PBC}$ to a greater extent than non-Asians.

However, only attitudes, but not subjective norms and $\mathrm{PBC}$, were important for organ donation intentions among Koreans (Bresnahan, Lee, Smith, Shearman, Nebashi, Park et al., 2007). Additionally, Bresnahan et al. (2007) found that attitudes and subjective norms were related to intentions to become a donor among Americans, whereas attitudes and PBC were related to those intentions among Japanese. One possible explanation for why attitudes are consistently related to intentions across cultures could be based on the characteristic of deceased organ donation. People may perceive organ donation as occurring after death, and thus intend to perform the behaviour in a distant future. According to construal level theory (Trope \& Liberman, 2003), individuals tend to consider abstract and general aspects of a behaviour when they perceive the behaviour in a distant future rather than in a near future, whereas individuals focus on concrete and pragmatic aspects of the same behaviour when they intend to perform it in a near future rather than in a distant future. The Asian participants in Bresnahan et al.s (2007) study might have been more likely to consider the general and abstract aspects of organ donation (i.e., general attitudes toward organ donation) than the more specific and pragmatic aspects of the behaviour that influenced subjective norms (i.e., consideration of others' opinions) or PBC (e.g., a lack of time to make necessary arrangements for signing an organ donor registry, ways to manage family objection to organ donation). When the behaviours under study are as specific as signing an organ donor registry and having family discussion about organ donation, however, individuals may consider subjective norms and PBC more importantly than attitudes.

The current study compares Americans with Koreans and examines the extent to which attitudes, subjective norms, and $\mathrm{PBC}$ are related to intentions to sign an organ donor registry and to have family discussion about organ donation. Korea is chosen as a culture with collectivist orientation and the United States as a culture with individualist orientation as Koreans tend to have fewer individualistic tendencies than Americans (Oyserman, Coon, \& Kemmelmeier, 2002). Based on the extant literature on organ donation, the current study asks two research questions. Research question 1 focuses on cross-cultural comparison and asks whether Americans would be more likely to rely on attitudes, subjective norms, and $\mathrm{PBC}$ than Koreans would, or vice versa, in forming intentions to sign and to have family discussion about organ donation. Research auestion 2 focuses on comparing TPB components and asks which of TPB components would be more important in influencing Americans' and Koreans' intentions.

\section{Method \\ Participants}

Participants were 290 American undergraduates (age $M$ $=20.26, S D=1.90,57 \%$ women) at a large Midwestern university in the U.S. and 292 Korean undergraduates

\section{Table 1}

Reliabilities, Correlations, Means, Standard Deviations, and t Test Results

\begin{tabular}{|c|c|c|c|c|c|c|c|c|}
\hline & BIS & AS & SNS & PBCS & BIT & AT & SNT & PBCT \\
\hline BIS & $(.96)$ & & & & & & & \\
\hline AS & $.53^{* *}$ & $(.80)$ & & & & & & \\
\hline SNS & $.54^{* *}$ & $.32 * *$ & $(.88)$ & & & & & \\
\hline PBCS & $.46^{* *}$ & $.37^{* *}$ & .41 ** & $(.79)$ & & & & \\
\hline BIT & $.61 * *$ & $.38^{* *}$ & $.40^{* *}$ & $.38^{* *}$ & $(.98)$ & & & \\
\hline AT & $.45^{* *}$ & $.64^{* *}$ & $.24^{* *}$ & .30 ** & $.49 * *$ & $(.87)$ & & \\
\hline SNT & $.50^{* *}$ & $.36^{* *}$ & $.52^{* *}$ & $.38^{* *}$ & $.60^{* *}$ & $.41^{* *}$ & $(.93)$ & \\
\hline PBCT & $.50^{* *}$ & $.40^{* *}$ & $.38^{* *}$ & $.49^{* *}$ & $.66^{* *}$ & $.48^{* *}$ & $.52^{* *}$ & $(.94)$ \\
\hline$M$ & 3.54 & 5.44 & 2.75 & 3.64 & 3.85 & 5.52 & 3.29 & 4.27 \\
\hline SD & $(1.60)$ & (1.05) & $(1.25)$ & (1.26) & (1.63) & (1.13) & (1.43) & $(1.62)$ \\
\hline Americans & $4.18(1.64)$ & $5.73(0.99)$ & $3.10(1.24)$ & $4.32(1.13)$ & 4.45 (1.64) & $5.80(1.09)$ & $3.64(1.33)$ & $5.21(1.26)$ \\
\hline Koreans & $2.97(1.33)$ & $5.16(1.03)$ & $2.43(1.19)$ & $3.03(1.06)$ & $3.30(1.43)$ & $5.28(1.12)$ & $2.97(1.45)$ & $3.41(1.41)$ \\
\hline $\mathrm{t}$ tests & $\begin{array}{c}t(518)=9.25 \\
p<.001 \\
\chi^{2}=.14\end{array}$ & $\begin{array}{c}t(516)=6.40 \\
p<.001 \\
\chi^{2}=.07\end{array}$ & $\begin{array}{c}t(518)=6.25 \\
p<.001 \\
\chi^{2}=.07\end{array}$ & $\begin{array}{c}t(518)=13.45 \\
p<.001 \\
\chi^{2}=.26\end{array}$ & $\begin{array}{c}t(516)=8.54 \\
p<.001 \\
\chi^{2}=.12\end{array}$ & $\begin{array}{c}t(517)=5.36 \\
p<.001 \\
\chi^{2}=.05\end{array}$ & $\begin{array}{c}t(516)=5.50 \\
p<.001 \\
\chi^{2}=.06\end{array}$ & $\begin{array}{c}t(517)=15.29 \\
p<.001 \\
\chi^{2}=.31\end{array}$ \\
\hline
\end{tabular}

Note: Reliabilities are reported in parentheses on the diagonal. ${ }^{* *} p<.01$

$\mathrm{BIS}=$ behavioural intention to sign an organ donor registry; $\mathrm{AS}=$ attitudes about signing an organ donor registry; SNS = subjective norms about signing an organ donor registry; PBCS = perceived behavioural control about signing an organ donor registry; BIT = behavioural intention to have family discussion; AT = attitudes about having family discussion; SNT = subjective norms about having family discussion; PBCT = perceived behavioural control about having family discussion. 
(age $M=21.76, S D=2.64,48 \%$ women) at three large universities in Seoul, Korea. Of American participants, $83.3 \%$ were Caucasian, $11.8 \%$ were African, $2.1 \%$ were Hispanic, and $2.7 \%$ were individuals with other ethnicities. All the Korean participants were ethnically Korean.

\section{Measures}

An English version of the survey questionnaire was constructed first, and then translated into Korean by a translator fluent in both languages. Items for all the variables were borrowed from previous studies on TPB (e.g., Park \& Smith, 2007). Cronbach's alpha, means, and standard deviations are reported in the Table 1.

Attitudes. Four 7-point semantic-differential scale items (good/bad, unwise/wise, favorable/unfavourable, beneficial/not beneficial) were used to measure attitudes toward signing an organ donor registry (e.g., 'Signing an organ donor registry is ...') and also to measure attitudes toward engaging in family discussion about organ donation (e.g., 'talking with family about organ donation'.). Some items were recoded in such a way that higher scores represented more positive attitudes (e.g., 1 $=$ Bad, $7=$ Good).

Subjective norms. Three items with a 7-point Likert scale ( 1 = Strongly disagree, $7=$ Strongly agree $)$ were used to measure subjective norms for signing an organ donor registry (e.g., 'Most people who are important to me think that I should sign the state organ donor registry'). Subjective norms for having family discussion about organ donation were also measured with three items (e.g., 'Most people who are important to me think that I should talk with my family about organ donation').

\section{Table 2}

Regression Results

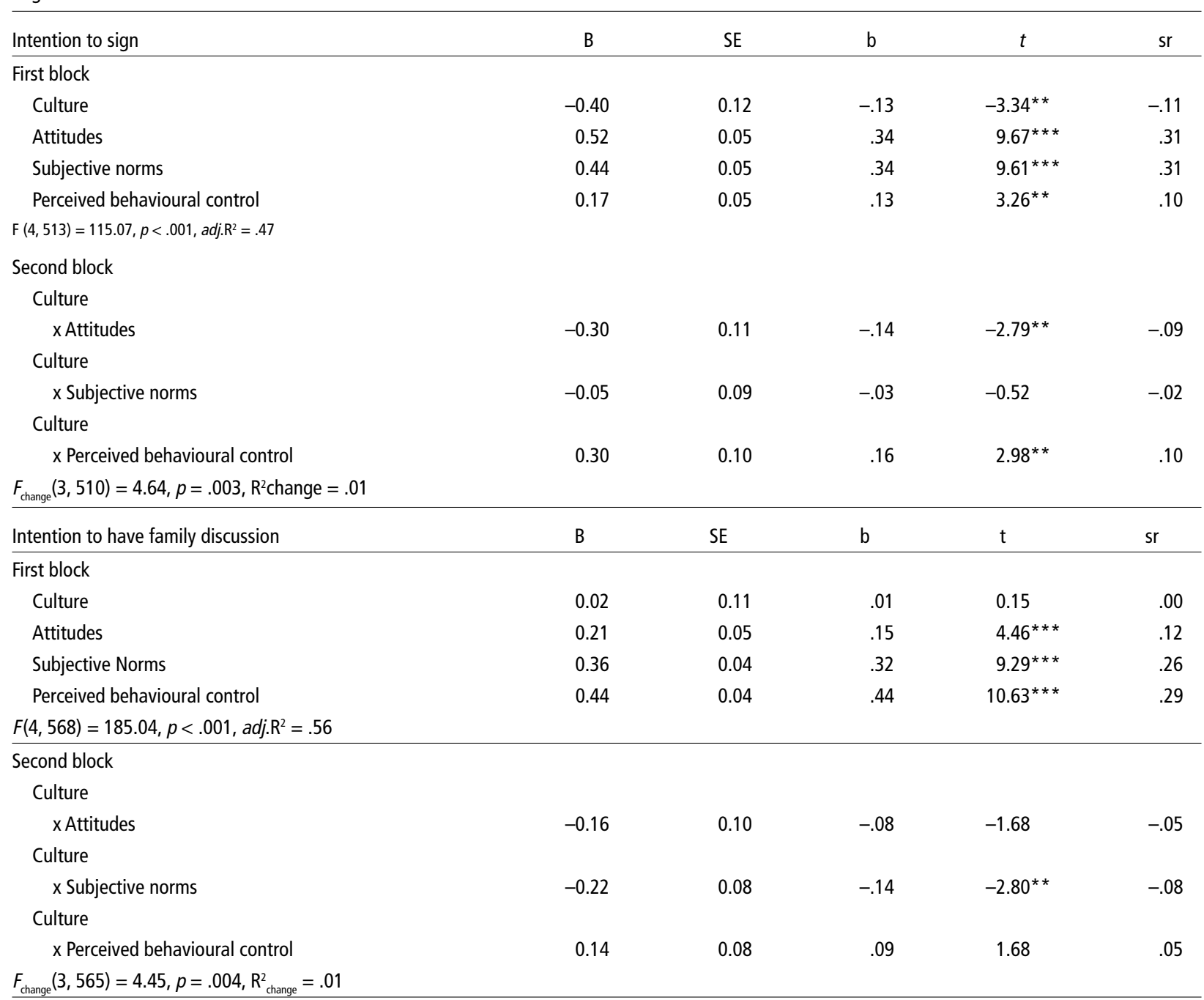

Note: ${ }^{*} p<.05,{ }^{* *} p<.01,{ }^{* *} p<.001$. Culture: Americans were coded as 0 and Koreans were coded as 1. PBC: perceived behavioural control; sr: semipartial correlation For intention to sign an organ donor registry, variance inflation factor (VIF) for the predictors ranged from 1.21 to 2.96 . For intention to have family discussion, VIF for the predictors ranged from 1.43 to 4.08 . These VIF values are lower than 10 as the traditional rule-of-thumb threshold value (Cohen et al., 2003, p. 424). Thus, multicollinearity does not pose a serious threat. 
Perceived behavioural control. Four items with a 7-point Likert scale $(1=$ Strongly disagree, $7=$ Strongly agree $)$ were used to measure $\mathrm{PBC}$ over signing an organ donor registry (e.g., 'It is easy to sign the State organ donor registry'). PBC over having family discussion about organ donation was also measured with four items (e.g., 'I am confident about talking with my family about organ donation').

Intentions. Four items with a 7-point Likert scale $(1=$ Strongly disagree, $7=$ Strongly agree) were used to measure intentions to sign an organ donor registry (e.g., 'I intend to sign the state organ donor web registry in the near future'). Four items were used to measure behavioural intentions to have family discussion about organ donation (e.g., 'I mean to talk with my family about organ donation in the near future').

\section{Results \\ Overview}

Before hierarchical multiple regression analyses, a categorical variable, culture, was dummy coded $(0=$ US and $1=$ Korea), and three continuous independent variables (attitudes, subjective norm, and PBC) were mean-centered to avoid multicollinearity. The first block of the regression analyses contained culture and three TPB components, followed by interaction terms between culture and TPB components in the second block. Table 2 shows regression analyses results.

\section{Intentions to Sign an Organ Donor Registry}

Participants who reported having signed were excluded from the analyses because they usually do not sign again. A total of 246 American and 275 Korean participants were included in the analyses. The overall model was significant, $F(7,510)=69.15, p<.001$, adj. $R^{2}=.48$. The predictors in the first block significantly contributed to intentions to sign, $F(4,513)=115.07, p<.001$, adj. $R^{2}=$ .47. The dummy-coded variable, culture $(\beta=-.13)$ was significant, indicating that Koreans were less likely to sign than Americans were. Attitudes $(\beta=.32)$, subjective norms $(\beta=.34)$, and $\mathrm{PBC}(\beta=.13)$ were significantly related to intentions to sign.

The predictors in the second block significantly contributed to intentions to sign, $F_{\text {change }}(3,510)=4.64, p=.003$, $R_{\text {change }}^{2}=.01 . \mathrm{RQ1}$ asked whether Americans or Koreans would be more likely to rely on attitudes, subjective norms, and $\mathrm{PBC}$ for their intentions. Results indicated that the interaction between culture and attitudes was significant, $\beta$ $=-.14$. The examination of simple slopes revealed that attitudes were a stronger predictor for intentions to sign among Americans $(\beta=.40)$ than among Koreans $(\beta=.28)$. However, the interaction between culture and subjective norms did not reach significance, $\beta=-.03$, indicating that subjective norms were related to the intentions to a similar extent among Americans $(\beta=.34)$ and Koreans $(\beta=.36)$. The interaction between culture and PBC was significant, $\beta=.16$. Examination of simple slopes showed that PBC was not significantly related to intentions among Americans $(\beta=.02)$, whereas it was among Koreans $(\beta$ $=.27$ ).

To answer RQ2 about the relative influence of attitudes, subjective norms, and $\mathrm{PBC}$ on intentions among each participant group, analyses were conducted following the procedure of comparing regression coefficients explained in Cohen, Cohen, West, and Aiken (2003). For Americans, attitudes $(\beta=.40)$ and subjective norms $(\beta=.34)$ contributed similarly to explaining variance in intentions, $t(241)=0.62, p>.05$. PBC $(\beta=.02)$ was not compared with attitudes and subjective norms because $\mathrm{PBC}$ was not a significant predictor for intentions among Americans. Among Koreans, attitudes $(\beta=.28)$ and subjective norms ( $\beta=.36)$ were related to intentions to a similar extent, $t(267)=1.32, p>.05$. Attitudes and PBC $(\beta=.27)$ contributed similarly to intentions, $t(267)=0.87, p>.05$. Subjective norms and PBC also did not differ in their relations to intentions, $t(267)=1.701, p>.05$.

\section{Intentions to Have Family Discussion}

For intentions to talk with family about organ donation, participants who had already performed the behaviour were included in the analyses because they may engage in family discussion again. The overall model was significant, $F(7,565)=109.57, p<.001$, adj. $R^{2}=.57$. The predictors in the first block significantly contributed to intentions to talk, $F(4,568)=185.04, p<.001$, adj. $R^{2}=$ .56. Culture was not significant $(\beta=.01)$, indicating that Koreans and Americans did not differ in intentions to talk. Attitudes $(\beta=.15)$, subjective norms $(\beta=.32)$, and PBC ( $\beta$ $=.44$ ) were significantly related to intentions to talk.

The interaction terms in the second block significantly contributed to intentions, $F_{\text {change }}(3,565)=4.45, p$ $=.004, R_{\text {change }}^{2}=.01$. For RQ1 about cross-cultural comparison, the interaction between culture and attitudes was not significant, $\beta=-.08$, indicating that strength of relationship between attitudes and the intentions did not differ between Americans $(\beta=.19)$ and Koreans $(\beta$ $=.10)$. However, the interaction between culture and subjective norms was significant, $\beta=-.14$. Subjective norms were related to intentions among Americans $(\beta=$ $.38)$ to a greater extent than among Koreans $(\beta=.23)$. The interaction between culture and $\mathrm{PBC}$ was not significant, $\beta=.09$. The predictive power of PBC did not differ significantly between Americans $(\beta=.32)$ and Koreans $(\beta=.52)$.

RQ2 asked the relative strengths of attitudes, subjective norms, and PBC. Among Americans, subjective norms ( $\beta=.38$ ) had a stronger influence on intentions than attitudes $(\beta=.19)$ did, $t(284)=3.41, p<.01$. In addition, $\mathrm{PBC}(\beta=.32)$ was a stronger predictor than attitudes $(\beta=.19)$ were, $t(284)=2.82, p<.01$. Subjective norms did not differ from PBC in their influences on intentions to talk, $t(284)=0.73, p>.05$. For Koreans, PBC $(\beta=.52)$ was a stronger predictor of 
intentions than subjective norms $(\beta=.23)$ were, $t(279)$ $=7.24, p<.01$. PBC was also a stronger predictor than attitudes $(\beta=.10)$ were, $t(279)=10.66, p<.01$. Lastly, subjective norms were more strongly related to the intentions than attitudes, $t(279)=3.99, p<.01$.

\section{Discussion}

\section{Summary and Interpretations}

Intentions to sign. The finding that the attitudes of Americans were more strongly related to intentions than those of Koreans may imply that Americans are more likely to perceive signing behaviour as having personal implications than Koreans. Results also showed that while American participants did not consider PBC in their intentions to sign, Korean participants did. These results indicate that Koreans might experience more difficulties in signing behaviour, resulting from cultural beliefs about organ donation (Kim, Elliott, \& Hyde, 2004) or some other barriers. On the other hand, a lack of cultural differences was observed in the relationship between subjective norms and intentions to sign. One possible explanation is that American participants might have perceived strong social pressure from important others towards signing an organ donor registry because of very favorable sentiments about organ donation in the United States (Gallop, 2005). On the other hand, Korean participants might have been influenced by opinions of important others as a result of their interpretation of signing behaviour as having social implications.

Intentions to talk. Attitudes were related to intentions among American and Korean participants to a similar extent. However, American participants were more likely to consider subjective norms than Korean participants were. One possible explanation is that American participants projected favorable sentiments about organ donation in the United States onto important others, and relied on subjective norms for the intentions to talk. Since family discussion involves other family members, and thus is more visible than signing behaviour, American participants might have been more influenced by subjective norms in their intentions to talk than in the intentions to sign. As a result, while American and Korean participants considered subjective norms to a similar extent for signing behaviour, American participants might have considered subjective norms to a greater extent for talking behaviour than Korean participants might. These findings indicate that signing an organ donor registry and family discussion are two distinct behaviours. The results that $\mathrm{PBC}$ was related to the intentions among American and Korean participants indicate that Americans, who may not find signing difficult, may find family discussion difficult, as Koreans may.

\section{Theoretical Implications}

Results from the current study suggest that cross-cultural studies of TPB needs to consider not only cultural differences in relevant dimensions (i.e., individualism/ collectivism), but also different interpretations of a behaviour across cultures. While some researchers found a stronger relationship between subjective norms and intentions among individuals from collectivistic cultures than among those from individualistic cultures (e.g., Chan \& Lau, 2001; Lee \& Green, 1990), other researchers found different patterns. For example, Park (1998) found that subjective norms were negatively related to Korean undergraduates' intentions to study for a final exam. The researcher explained the results based on characteristics of the population from which the study sample was drawn and the meaning of the behaviour, not based on individualism/collectivism cultural differences. Attention to different meanings which participants in each culture attach to a behaviour is also relevant to a cross-cultural study of TPB.

In addition to subjective norms, attitudes and $\mathrm{PBC}$ also influence individuals' intentions to perform a behaviour as a result of different interpretations of the behaviour. Although studies based on individuals from individualistic cultures reported that the relationship between attitudes and intentions was stronger than the relationship between subjective norms and intentions (Armitage \& Conner, 2001), results from the current study showed that attitudes were less important than subjective norms when the behaviour involves others such as engaging family members to discuss about organ donation. $\mathrm{PBC}$ can be more important than attitudes because of difficulty in engaging family members to discuss about organ donation.

\section{Implications for Communication Campaigns}

The current study has implications for communication campaigns about organ donation in the United States and Korea. First, communication campaigns need to address discrepancies between individuals' attitudes and subjective norms in both the United States and Korea. Results showed that participants were less influenced by subjective norms than by attitudes about signing and having family discussion, indicating that individuals may perceive that their important others have less favourable attitudes about the behaviours than they do. Given the positive relationship between subjective norms and the two behaviours in both countries, information about accurate (or higher) level of subjective norms might be beneficial. A recent study also found that a normative message about organ donation increased college students' willingness to communicate about organ donation (Marshall \& Feeley, 2006), although the effect was rather small.

Second, communication campaigns may be successful when they focus on PBC. For example, campaigns may provide factual information about organ donation and useful family communication techniques so that individuals willing to donate their organs would be equipped with 
the necessary information to support their position during family communication about the issue. Lastly, for an attempt to influence Americans' intentions to engage in family discussion, campaigns may be successful when they prioritise subjective norms and $\mathrm{PBC}$ over attitudes. For Koreans, more focus on PBC than on attitudes and subjective norms would be successful.

\section{Limitations}

The use of undergraduate samples in the current study can be seen as a limitation; thus, results from the current study may lack generalisability to non-student samples in the United States and Korea. However, the current findings can be useful for organ donation campaigns targeting college students in the United States and Korea because the characteristics of college students (e.g., socioeconomical status) tend to match those of individuals who are more likely to donate in the U.S. (Feeley \& Servoss, 2005) and because this age group in Korea (from 18 to 34 years old) is most likely to donate organs (Korean Network for Organ Sharing, 2009).

Another limitation is that the American sample in the current study was not large enough for examining the possibility of ethnic differences. Previous studies found that Americans with different ethnicities (e.g., white Americans, black Americans, Asian Americans, native Americans) showed similarities as well as differences in intentions and attitudes regarding signing an organ donor registry and family discussion about organ donation (Park, Shin, \& Yun, 2009; Park, Smith, \& Yun, 2009). Future studies with larger samples or ethnically stratified random samples may need to examine various ethnic and national differences.

Finally, the current study focused on intentions rather than actual behaviours. Future studies needs to examine whether or not intentions are predictive of the behaviours needs to be examined. Although a meta-analysis of 10 meta-analyses with correlational data (Sheeran, 2002) and a meta-analysis of the experimental evidence (Webb \& Sheeran, 2006) provided strong evidence that intentions are predictive of behaviours, it has also been noted that a variety of factors (e.g., behaviour types, measurement artifacts, etc.) could affect the strength of the relationship between intentions and behaviours (Sheeran, 2002; Webb \& Sheeran, 2006). Additionally, a previous study showed that willingness to engage in family discussion about organ donation was significantly related to the selfreported behaviour of family discussion a week later (Park, Yun, Smith, \& Morrison, 2010). But there is still the possibility of inconsistency between intentions and behaviours for the behaviours of signing an organ donor registry and having family discussion.

\section{Conclusion}

Individuals from different cultures may consider different reasons when they form intentions to perform or not perform certain behaviours because they attach meanings to those behaviours unique and specific to their culture. As the current findings indicate, although both signing an organ donor registry and talking with family about organ donation are two behaviours for the same goal of enabling deceased organ donation, different predictors were important for behavioural intentions among Koreans versus Americans. Thus, examination of a specific behaviour through its cultural meanings is necessary in studies that look at cross-cultural comparisons of TPB for theoretical and practical implications.

\section{References}

Ajzen, I. (1985). From intentions to actions: A theory of planned behavior. In J. Kuhl \& J. Beckman (Eds.), Actioncontrol: From cognitions to behavior (pp. 11-39). Heidelberg, Germany: Springer.

Ajzen, I. (1988). Attitudes, personality and behavior. MiltonKeynes, UK: Open University Press.

Armitage, C.J., \& Conner, M. (2001). Efficacy of the theory of planned behaviour: A meta-analytic review. British Journal of Social Psychology, 40, 471-499.

Braun, K.L., \& Nichols, R. (1996). Cultural issues in death and dying. Hawaii Medical Journal, 55, 260-264.

Bresnahan, M., Lee, S.Y., Smith, S.W., Shearman, S., Nebashi, R., Park, C.Y., \& Yoo, J. (2007). A theory of planned behavior study of college students' intention to register as organ donors in Japan, Korea, and the United States. Health Communication, 21, 201-211.

Chan, R.Y.K., \& Lau, L.B.Y. (2001). Explaining green purchasing behavior: A cross-cultural study on American and Chinese consumers. Journal of International Consumer Marketing, 14, 9-40.

Cohen, J., Cohen, P., West, S.G., \& Aiken, L.S. (2003). Applied multiple regression/correlation analysis for the behavioral sciences (3rd ed.). Mahwah, NJ: LEA.

Feeley, T.H., \& Servoss, T.J. (2005). Examining college students' intentions to become organ donors. Journal of Health Communication, 10, 237-249.

Fishbein, M., \& Ajzen, I. (1975). Belief, attitude, intention, and behavior: An introduction to theory and research. Reading, MA: Addison-Wesley.

Gallop Organization. (2005). 2005 national survey of organ and tissue donation attitudes and behaviors. Washington, DC: The Gallop Organization.

Godin, G., \& Kok, G. (1996). The theory of planned behavior: A review of its applications to health-related behaviors. American Journal of Health Promotion, 11, 87-98.

Godin, G., Maticka-Tynadale, E., Adrien, A., Manson-Singer, S., Williams, D., \& Cappon, P. (1996). Cross-cultural testing of three social cognitive theories: An application to condom use. Journal of Applied Social Psychology, 26, 1556-1586.

Institute of Medicine of the National Academies (2006). Organ donation: Opportunities for action. Washington, DC: National Academies Press.

Kim, J.R., Elliott, D., \& Hyde, C. (2004). The influence of sociocultural factors on organ donation and transplantation in 
Korea: Finding from key informant interviews. Journal of Transcultural Nursing, 15, 147-154.

Korean Network for Organ Sharing. (2009). Retrieved June 01, 2008, from http://www.konos.go.kr

Lee, C., \& Green, R.T. (1991). Cross-cultural examination of the Fishbein behavioral intentions model. Journal of International Business Studies, 22, 289-305.

Markus, H.R., \& Kitayama, S. (1991). Culture and the self: Implications for cognition, emotion, and motivation. Psychological Review, 98, 224-253.

Marshall, H.M., \& Feeley, T.H. (2006). A normative approach to shaping college students' attitudes toward organ donation. Communication Studies, 57, 435-453.

Markus, H.R., \& Kitayama, S. (1991). Culture and the self: Implications for cognition, emotion, and motivation. Psychological Review, 98, 224-253.

Molzahn, A.E., Starzomski, R., McDonald, M., \& O’Loughlin, C. (2005). Chinese Canadian beliefs toward organ donation. Qualitative Health Research, 15, 82-98.

Oyserman, D., Coon, H.M., \& Kemmelmeier, M. (2002). Rethinking individualism and collectivism: Evaluation of theoretical assumptions and meta-analyses. Psychological Bulletin, 128, 3-72.

Park, H.S. (2000). Relationships among attitudes and subjective norms: Testing the theory of reasoned action across cultures. Communication Studies, 51, 162-175.

Park, H.S., \& Lee, D.W. (2009). A test of theory of planned behavior in Korea: Participation in alcohol-related social gatherings. International Journal of Psychology, 44, 418-433.

Park, H.S., Shin, Y.S., \& Yun, D. (2009). Differences between white Americans and Asian Americans for social responsibility, individual right, and intentions regarding organ donation. Journal of Health Psychology, 14, 709-714.

Park, H.S., \& Smith, S.W. (2007). Distinctiveness and influence of subjective norms, personal descriptive and injunctive norms, and societal descriptive and injunctive norms on behavioral intent: A case of two behaviors critical to organ donation. Human Communication Research, 33, 194-218.

Park, H.S., Smith, S.W., \& Yun, D. (2009). Ethnic differences in intention to enroll in a state organ donor registry and intention to talk with family about organ donation. Health Communication, 24, 647-659.

Park, H.S., Yun, D., Smith, S.W., \& Morrison, K. (2010). Family communication patterns and willingness to engage in family discussion about organ donation in the United States. Global Journal of Health Science, 2(2), 61-71.

Pepitone, A., \& Triandis, H.C. (1987). On the universality of social psychological theories. Journal of Cross Cultural Psychology, 18, 471-198.

Sheeran, P. (2002). Intention-behavior relations: A conceptual and empirical review. In W. Stroebe \& M. Hewstone (Eds.), European review of social psychology (Vol. 12, pp. 134). Chichester, UK: John Wiley \& Sons.

Sheppard, B.H., Hartwick, J., \& Warshaw, P.R. (1988). The theory of reasoned action: A meta-analysis of past research with recommendations for modifications and future research. Journal of Consumer Research, 15, 325-343.

Triandis, H.C. (1995). Individualism and collectivism. Boulder, CO: Westview Press.

Trope, Y., \& Liberman, N. (2003). Temporal construal. Psychological Review, 110, 403-421.

United Network for Organ Sharing (2009). Organ Procurement and Transplantation Network. Retrieved May 30, 2009, from www.OPTN.org

Webb, T.L., \& Sheeran, P. (2006). Does changing behavioral intentions engender behavior change?: A meta-analysis of the experimental evidence. Psychological Bulletin, 132, 249 268. 